\title{
Effects of Amlodipine on the Pharmacokinetics of Warfarin after Oral and Intravenous Administration of Warfarin in Rats
}

\author{
Dong-Hyun Choi ${ }^{1}$, Yong-Ji Piao ${ }^{2}$, Eun-Joo Choi ${ }^{3}$, Jun-Shik Choi ${ }^{3}$ and Jin-Pil Burm ${ }^{4, *}$ \\ ${ }^{1}$ College of Medicine, ${ }^{3}$ College of Pharmacy, Chosun University, Gwangju 501-759, Republic of Korea, \\ ${ }^{2}$ Shenzhen Salubris Pharmaceuticals Co., Baoan District, Shengzhen 518-040, China, \\ ${ }^{4}$ College of Nursing, Chosun Nursing College, Gwangju 501-825, Republic of Korea
}

\begin{abstract}
The aim of this study was to investigate the effect of amlodipine on the pharmacokinetics of warfarin after oral and intravenous administration of warfarin in rats. Warfarin was administered orally $(0.2 \mathrm{mg} / \mathrm{kg})$ or intravenously $(0.05 \mathrm{mg} / \mathrm{kg})$ without or with oral administration of amlodipine $(0.1$ or $0.4 \mathrm{mg} / \mathrm{kg})$ in rats. The effect of amlodipine on the P-glycoprotein (P-gp) as well as cytochrome P450 (CYP) 3A4 activity was also evaluated. Amlodipine inhibited CYP3A4 enzyme activity with $50 \%$ inhibition concentration $\left(\mathrm{IC}_{50}\right)$ of $9.1 \mu \mathrm{M}$. Compared to those animals in the oral control group (warfarin without amlodipine), the area under the plasma concentration-time curve (AUC) of warfarin was significantly greater $(0.1 \mathrm{mg} / \mathrm{kg}, p<0.05 ; 0.4 \mathrm{mg} / \mathrm{kg}, \quad p<0.01)$ by $26.5-53.5 \%$, and the peak plasma concentration $\left(C_{\text {max }}\right)$ was significantly higher $(0.4 \mathrm{mg} / \mathrm{kg}, p<0.05)$ by $26.2 \%$ after oral administration of warfarin with amlodipine, respectively. Consequently, the relative bioavailability of warfarin increased by $1.26-$ to $1.53-$ fold and the absolute bioavailability of warfarin with amlodipine was significantly greater by $61.7-72.5 \%$ compared to that in the control group (47.4\%). In contrast, amlodipine had no effect on any pharmacokinetic parameters of warfarin given intravenously. Therefore, the enhanced oral bioavailability of warfarin may be due to inhibition of CYP 3A4-mediated metabolism in the intestine and/or liver rather than renal elimination and P-gp by amlodipine.
\end{abstract}

Key Words: Amlodipine, Warfarin, Pharmacokinetics, P-glycoprotein, CYP3A4, Rats

\section{INTRODUCTION}

Amlodipine, a dihydropyridine calcium channel blocker, causes coronary and peripheral vasodilatation by blocking the influx of extracellular calcium across cell membranes. Amlodipine is arterioselective and effective for the treatment of hypertension, myocardial ischemia, and vasospasm in surgical patients (Kungys et al., 2003). Amlodipine is rapidly absorbed and is extensively metabolized in the liver while it shows linear dose-related pharmacokinetic characteristics and, at steadystate, there are relatively small fluctuations in plasma concentrations across a dosage interval (Abernethy, 1992). Although structurally related to other dihydropyridine derivatives, amlodipine displays significantly different pharmacokinetic characteristics (Meredith et al., 1992). Amlodipine is a substrate of cytochrome P450 (CYP) 3A subfamily, specifically CYP3A4 (Nishio et al., 2005; Kim et al., 2009). In addition, amlodipine is also a P-glycoprotein (P-gp) substrate (Darvari and Boroujerdi, 2004; Harmsze et al., 2010).

Warfarin is the most extensively used oral anticoagulant for the prevention and treatment of thromboembolic complica-

www.biomolther.org

Open Access http://dx.doi.org/10.4062/biomolther.2011.19.4.493

pISSN: 1976-9148 elSSN: 2005-4483

Copyright $\odot 2011$ The Korean Society of Applied Pharmacology tions in cardiovascular diseases such as atrial fibrillation, venous thrombosis and pulmonary embolism (Hirsh et al., 1998). Warfarin's anticoagulant effect is due to its interference with the cyclic interconversion of vitamin $\mathrm{K}$ and its 2, 3 epoxide, and to its limitation of the synthesis of the vitamin K-dependent clotting factors, II, VII, IX and X (Scordo et al., 2002; Wallin et al., 2002). Warfarin is readily absorbed from the gastrointestinal tract, extensively bound to plasma proteins. Warfarin is used as a racemic mixture of roughly equal amounts of $R$ and $S$ enantiomers yet S-warfarin has been reported to be more potent (Mungall, 1985). Warfarin is metabolized by CYPs and is converted to inactive metabolites through selective hydroxylation (Holford, 1986). R-warfarin is metabolized primarily by CYP3A4 to 10-hydroxywarfarin and S-warfarin is metabolized primarily by CYP2C9 to 7-hydroxywarfarin. Potential warfarindrug interactions could occur with any of a very wide range of drugs that are metabolized by these CYPs, and a number of such interactions have been reported (Kaminsky et al., 1997).

However, there have been no reports regarding the effects of amlodipine on the bioavailability or pharmacokinetics of warfarin in rats. Moreover, amlodipine and warfarin could be

Received Apr 5, 2011 Revised Aug 30, 2011 Accepted Sep 1, 2011

*Corresponding Author
E-mail: jpburm@cnc.ac.kr
Tel: +82-62-231-7361, Fax: +82-62-232-9072 
prescribed for the prevention or treatment of thromboembolism and ischemic stroke in some patients with atrial fibrillation, valvular heart disease and a myocardial infarction as a combination therapy. Warfarin has a narrow therapeutic range and its efficacy can be influenced by drug-drug interactions. Therefore, the present study aimed to investigate the effects of amlodipine on the pharmacokinetics of warfarin after oral and intravenous administration in rats.

\section{MATERIALS AND METHODS}

\section{Chemicals and apparatus}

Warfarin, amlodipine and 7-ethoxycoumarin (internal standard for high-performance liquid chromatograph analysis of warfarin) were purchased from Sigma-Aldrich Co. (St. Louis, MO, USA). HPLC grade acetonitrile was a purchased from Merck Co. (Darmstadt, Germany). Other chemicals for this study were reagent grade.

The HPLC system used in this study was comprised of a Waters 1515 isocratic HPLC pump, a Waters 717 plus autosampler and a Waters ${ }^{\mathrm{TM}} 474$ scanning fluorescence detector (Waters Co., Milford, MA, USA), a HPLC column temperature controller (Phenomenex Inc., CA, USA), a Bransonic ${ }^{\circledR}$ Ultrasonic Cleaner (Branson Ultrasonic Co., Danbury, CT, USA), a vortex-mixer (Scientific Industries Co., NY, USA) and a highspeed micro centrifuge (Hitachi Co., Tokyo, Japan).

\section{Animal experiments}

Male Sprague-Dawley rats 7-8 weeks of age (weighing 270-300 g) were purchased from Dae Han Laboratory Animal Research Co. (Choongbuk, Republic of Korea) and given free access to a commercial rat chow diet (No. 322-7-1; Superfeed Co., Gangwon, Republic of Korea) and tap water. The animals were housed, two per cage, maintained at $22 \pm 2^{\circ} \mathrm{C}$ and $50-60 \%$ relative humidity under a $12: 12 \mathrm{~h}$ light-dark cycle. The rats were acclimated under these conditions for at least 1 week. All animal studies were performed in accordance with the "Guiding Principles in the Use of Animals in Toxicology" adopted by the Society of Toxicology (USA) and the Animal Care Committee of Chosun University (Gwangju, Republic of Korea) approved the protocol of this animal study. The rats were fasted for at least $24 \mathrm{~h}$ prior to beginning the experiments and had free access to tap water. Each animal was anaesthetized with light ether. The left femoral artery and vein were cannulated using polyethylene tubing (SP45, I.D. $0.58 \mathrm{~mm}$, O.D. 0.96 mm; Natsume Seisakusho Co. LTD., Tokyo, Japan) for blood sampling and drug administration, respectively.

\section{Oral and intravenous administration of warfarin}

The rats were randomly divided into four groups $(n=6$, each); an oral group ( $0.2 \mathrm{mg} / \mathrm{kg}$ of warfarin dissolved in water; homogenized at $36^{\circ} \mathrm{C}$ for $30 \mathrm{~min} ; 1.0 \mathrm{ml} / \mathrm{kg}$ ) without (control) or with 0.1 or $0.4 \mathrm{mg} / \mathrm{kg}$ of oral amlodipine, and an intravenous group $(0.05 \mathrm{mg} / \mathrm{kg}$ of warfarin, dissolved in $0.9 \% \mathrm{NaCl}-$ injectable solution; homogenized at $36^{\circ} \mathrm{C}$ for $30 \mathrm{~min} ; 0.3 \mathrm{ml} /$ $\mathrm{kg}$ ) without (control) or with 0.1 or $0.4 \mathrm{mg} / \mathrm{kg}$ of oral amlodipine. Warfarin was administered orally using a gastric gavage tube, and amlodipine was orally administered $30 \mathrm{~min}$ prior to oral or intravenous administration of warfarin. Warfarin for intravenous administration was injected through the femoral vein within $0.5 \mathrm{~min}$. A blood sample $(0.3 \mathrm{ml})$ was collected into heparinized tubes from the femoral artery at 0 (control), 0.25 , $0.5,1,2,4,8,12,24$ and $36 \mathrm{~h}$ after intravenous infusion, and $1,2,3,4,5,6,8,12,24,36,48$ and $72 \mathrm{~h}$ after oral administration. The blood samples were centrifuged (13,000 rpm, $5 \mathrm{~min})$, and the plasma samples $(0.15 \mathrm{ml})$ were stored at $-40^{\circ} \mathrm{C}$ until HPLC analysis of warfarin. An approximately $1 \mathrm{ml}$ of whole blood collected from untreated rats was infused via the femoral artery at $0.25,1,3$ and $8 \mathrm{~h}$, respectively, to replace blood loss due to blood sampling.

\section{HPLC assay}

The plasma concentrations of warfarin were determined by a HPLC assay method reported by Zhu et al. (1999). Briefly, $50 \mu \mathrm{l}$ of 7-ethoxycoumarin ( $2 \mu \mathrm{g} / \mathrm{ml}$ dissolved in methanol), 50 $\mu \mathrm{l}$ of methanol, $200 \mathrm{ml}$ distilled water, $0.5 \mathrm{ml}$ of $2 \mathrm{M}$ hydrochloric acid, and $0.8 \mathrm{ml}$ of diethyl ether were added to $0.15 \mathrm{ml}$ of plasma sample. The mixture was then stirred for $10 \mathrm{~min}$ and centrifuged (13,000 rpm, $10 \mathrm{~min}) .0 .7 \mathrm{ml}$ of the organic layer was transferred to a clean test tube and evaporated under a gentle stream of nitrogen at $35^{\circ} \mathrm{C}$. The residue was dissolved in $150 \mu \mathrm{l}$ of the phosphate buffer. Next, $70 \mu \mathrm{l}$ of the supernatant was injected into the HPLC system. Chromatographic separations were achieved using a guard column packed with $\mathrm{C}_{18}$ column $(4 \times 3.0 \mathrm{~mm}, 5 \mu \mathrm{m}$, Phenomenex), and a reversedphase Luna ${ }^{\circledR} \mathrm{C}_{18}$ column $(4.6 \times 150 \mathrm{~mm}, 5 \mu \mathrm{m}$, Phenomenex). The mobile phase was $10 \mathrm{mM}$ phosphate buffer-methanol $(50: 50, v / v)$, which was run at a flow rate of $1.0 \mathrm{ml} / \mathrm{min}$. Chromatography was performed at a temperature of $30^{\circ} \mathrm{C}$ that was set by an HPLC column temperature controller, while the UV detector was set to $300 \mathrm{~nm}$. The retention times of warfarin and the internal standard were 16.7 and $9.1 \mathrm{~min}$, respectively. The detection limit of warfarin in rat's plasma was $5 \mathrm{ng} / \mathrm{ml}$. The coefficients of variation for warfarin were below $12.8 \%$.

\section{CYP inhibition assay}

The inhibition assays of human CYP3A4 enzyme activity were performed in a multiwell plate using the CYP inhibition assay kit (BD Bioscience, San Jose, CA) as described previously (Crespi et al., 1997). Briefly, human CYP enzymes were obtained from baculovirus-infected insect cells. CYP3A4 substrate (7-Benzyloxy-4-(trifluoromethyl) couamrin (BFC)) was incubated with or without test compounds in a reaction mixture containing 1 pmol of CYP3A4 enzyme and the NADPH-generating system (1.3 mM NADP, $3.54 \mathrm{mM}$ glucose 6-phosphate, $0.4 \mathrm{U} / \mathrm{ml}$ glucose 6-phosphate dehydrogenase and $3.3 \mathrm{mM} \mathrm{MgCl}$ ) in potassium phosphate buffer ( $\mathrm{pH} 7.4)$. Reactions were terminated by adding stop solution after 45 min. Metabolite concentrations were measured with a spectrofluorometer (Molecular Device, Sunnyvale, CA) set at an excitation wavelength of $409 \mathrm{~nm}$ and an emission wavelength of $530 \mathrm{~nm}$. Positive control ( $1 \mu \mathrm{M}$ ketoconazole) was run on the same plate and produced $99 \%$ inhibition. All experiments were performed in duplicate, and the results are expressed as the percent of inhibition.

\section{Rhodamine-123 retention assay}

The procedures used for the rhodamine-123 retention assay were similar to a previously reported method (Han et al., 2008). NCl/ADR-Res cells was seeded in 24-well plates. At $80 \%$ confluence, the cells were incubated in fetal bovine serum (FBS)-free Dulbecco's modified Eagle's medium (DMEM) for $18 \mathrm{~h}$. The culture medium was changed with Hanks' bal- 

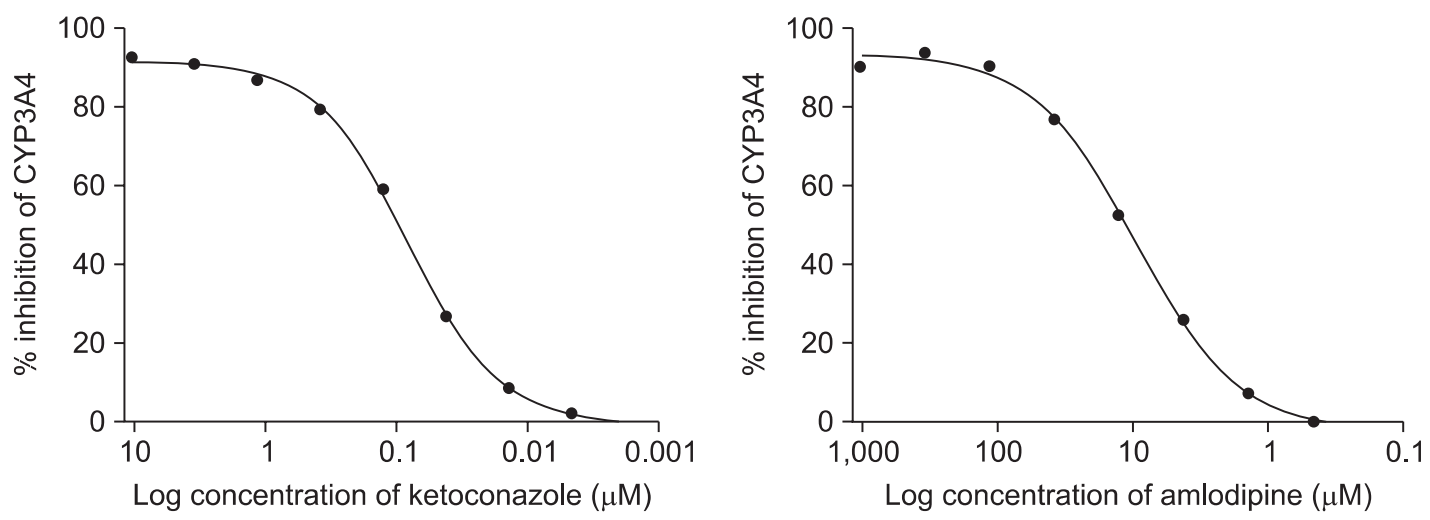

Fig. 1. Inhibitory effect of ketoconazole and amlodipine on CYP3A4 activity. All experiments were performed in duplicate, and results were expressed as the percent of inhibition $\left(\mathrm{IC}_{50}: 9.1 \mu \mathrm{M}\right)$. Ketoconazole $(1 \mu \mathrm{M})$ was used as a positive control.

anced salt solution and the cells were incubated at $37^{\circ} \mathrm{C}$ for 30 min. After incubation of the cells with $20-\mu \mathrm{M}$ rhodamine-123 in the presence or absence of amlodipine $(10,30$ or $100 \mu \mathrm{M})$ or verapamil $(100 \mu \mathrm{M})$ for $90 \mathrm{~min}$, the medium was completely aspirated. The cells were then washed three times with an ice-cold phosphate buffer $(\mathrm{pH} \mathrm{7.0)}$ and lysed in lysis buffer. The rhodamine-123 fluorescence in the cell lysates was measured using excitation and emission wavelengths of 480 and $540 \mathrm{~nm}$, respectively. Fluorescence values were normalized to the total protein content of each sample and presented as the percentage ratio to control.

\section{Pharmacokinetic analysis}

The pharmacokinetic parameters were calculated using non-compartmental analysis (WinNonlin; software version 4.1; Pharsight Co., Mountain View, CA, USA). The elimination rate constant $\left(\mathrm{K}_{\mathrm{el}}\right)$ was calculated by log-linear regression of warfarin concentration data during the elimination phase, and the terminal half-life $\left(\mathrm{t}_{1 / 2}\right)$ was calculated by $0.693 / \mathrm{K}_{\mathrm{el}}$. The peak plasma concentration $\left(\mathrm{C}_{\max }\right)$ and time to reach peak plasma concentration $\left(T_{\max }\right)$ of warfarin were directly read from the experimental data. The area under the plasma concentrationtime curve $\left(A \cup C_{0-t}\right)$ from time zero to the time of last measured concentration $\left(\mathrm{C}_{\text {last }}\right)$ was calculated by the linear trapezoidal rule. The $A \cup C$ zero to infinite $\left(A \cup C_{0-\infty}\right)$ was obtained by the addition of $\mathrm{AUC}_{0-\mathrm{t}}$ and the extrapolated area determined by $\mathrm{C}_{\text {ast }} / \mathrm{K}_{\mathrm{el}}$. Total body clearance $(\mathrm{CL})$ was calculated by Dose/ AUC. The absolute bioavailability (A.B.) of warfarin was calculated by AUC oral $/ A \cup C_{\text {intravenous }} \times$ Dose $_{\text {intravenous }} /$ Dose $_{\text {oral }} \times 100$, and the relative bioavailability (R.B.) of warfarin was estimated by $A \cup C_{\text {with amlodipine }} / \mathrm{AUC}_{\text {control }} \times 100$.

\section{Statistical analysis}

All data were expressed with their standard deviation (mean \pm S.D.). Statistical analysis was conducted using a one-way analysis of variance (ANOVA) followed by a posteriori testing with Dunnett's correction. Differences were considered significant at a level of $p<0.05$.

\section{RESULTS}

Inhibitory effect of amlodipine on CYP3A4 activity

The inhibitory effect of amlodipine on CYP3A4 activity is

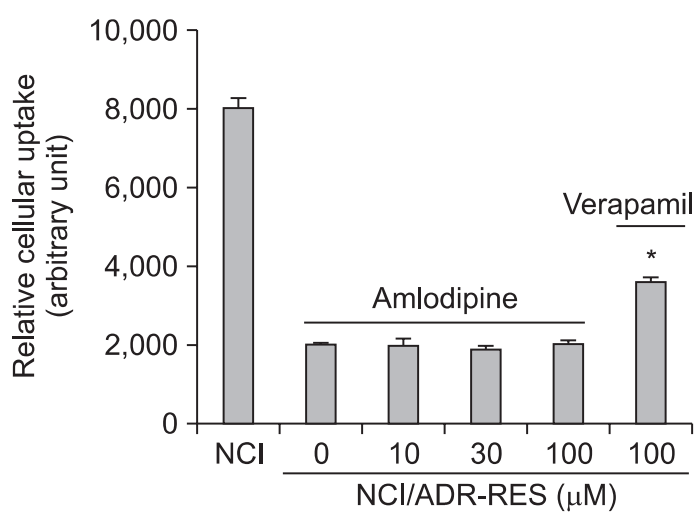

Fig. 2. Rhodamine-123 retention. NCI/ADR-RES cells were preincubated with amlodipine for $30 \mathrm{~min}$, and after incubation of $\mathrm{NCl} /$ ADR-RES cells with $20 \mu \mathrm{M} R-123$ for $90 \mathrm{~min}$. The values were divided by total protein contents of each sample. Verapamil (100 $\mu \mathrm{M})$ was used as a positive control. Data represents mean $\pm S D$ of 6 separate samples $\left({ }^{*} p<0.05\right)$.

shown in Fig. 1. Amlodipine inhibited CYP3A4 enzyme activity and the $50 \%$ inhibition concentration $\left(\mathrm{IC}_{50}\right)$ value of amlodipine o n CYP3A4 activity was $9.1 \mu \mathrm{M}$.

\section{Rhodamine- 123 retention assay}

As shown in Fig. 2. The concurrent use of amlodipine did not enhance the cellular uptake of rhodamine-123 in a concentration-dependent manner ranging from 10-100 $\mu \mathrm{M}$. This result suggests that amlodipine did not significantly inhibit P-gp activity.

\section{Effect of amlodipine on the pharmacokinetics of warfarin after oral administration}

The mean arterial plasma concentration-time profiles of warfarin after oral administration of warfarin $(0.2 \mathrm{mg} / \mathrm{kg})$ with or without amlodipine $(0.1$ and $0.4 \mathrm{mg} / \mathrm{kg})$ are shown in Fig. 3. The relevant pharmacokinetic parameters of warfarin are also listed in Table 1. The AUC of warfarin was significantly greater $(0.1 \mathrm{mg} / \mathrm{kg}, p<0.05 ; 0.4 \mathrm{mg} / \mathrm{kg}, p<0.01)$ by $26.5-53.5 \%$, and the $\mathrm{C}_{\max }$ was significantly higher $(0.4 \mathrm{mg} / \mathrm{kg}, p<0.05)$ by $26.2 \%$ after oral administration of warfarin with amlodipine. Consequently, the relative bioavailability of warfarin was increased 1.26- to 1.53-fold and the absolute bioavailability of warfarin 


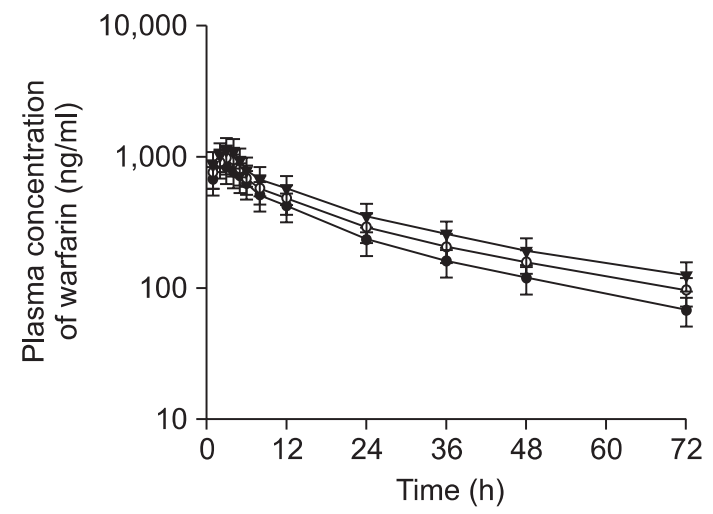

Fig. 3. Mean arterial plasma concentration-time profiles of warfarin after oral administration of warfarin $(0.2 \mathrm{mg} / \mathrm{kg})$ without $(0)$ or with $0.1 \mathrm{mg} / \mathrm{kg}(\bigcirc)$ and $0.4 \mathrm{mg} / \mathrm{kg}(\boldsymbol{\nabla})$ of amlodipine in rats. Bars represent the standard deviation $(n=6)$.

Table 1. Mean pharmacokinetic parameters of warfarin after oral administration of warfarin $(0.2 \mathrm{mg} / \mathrm{kg})$ with or without amlodipine $(0.1$ and 0.4 $\mathrm{mg} / \mathrm{kg}$ ) in rats

\begin{tabular}{lccc}
\hline \multirow{2}{*}{ Parameters } & \multirow{2}{*}{$\begin{array}{c}\text { Control without } \\
\text { amlodipine }\end{array}$} & \multicolumn{2}{c}{ With amlodipine } \\
\cline { 3 - 4 } & & $0.1 \mathrm{mg} / \mathrm{kg}$ & $0.4 \mathrm{mg} / \mathrm{kg}$ \\
\hline $\mathrm{AUC}(\mathrm{ng} \cdot \mathrm{h} / \mathrm{ml})$ & $19810 \pm 3358$ & $25054 \pm 4510^{*}$ & $30417 \pm 6689^{* *}$ \\
$\mathrm{C}_{\max }(\mathrm{ng} / \mathrm{ml})$ & $882 \pm 152$ & $972 \pm 211$ & $1113 \pm 202^{*}$ \\
$\mathrm{~T}_{\max }(\mathrm{h})$ & 2.0 & 3.0 & 3.0 \\
$\mathrm{t}_{1 / 2}(\mathrm{~h})$ & $27.6 \pm 3.1$ & $31.6 \pm 5.4$ & $33.0 \pm 4.6^{*}$ \\
A.B. $(\%)$ & $47.4 \pm 8.8$ & $61.7 \pm 12.5^{*}$ & $72.5 \pm 15.1^{* *}$ \\
R.B. $(\%)$ & 100 & 126 & 153 \\
\hline
\end{tabular}

Mean \pm S.D. $(n=6),{ }^{*} p<0.05,{ }^{* *} p<0.01$, significant difference compared to controls, AUC: area under the plasma concentration-time curve from $0 \mathrm{~h}$ to time infinity, $\mathrm{C}_{\text {max }}$ : peak plasma concentration, $\mathrm{T}_{\max }$ : time to reach peak concentration, $\mathrm{t}_{1 / 2}$ : terminal half-life, A.B. (\%): absolute bioavailability, R.B. (\%): relative bioavailability.

with amlodipine was significantly greater by $61.7-72.5 \%$ compared to that in the control group (47.4\%). The half-life of warfarin was significantly longer $(0.4 \mathrm{mg} / \mathrm{kg}, p<0.05)$ and there was no significant change in the $T_{\max }$.

\section{Effect of amlodipine on the pharmacokinetics of warfarin} after intravenous administration

The mean arterial plasma concentration-time profiles of warfarin after intravenous administration of warfarin $(0.05 \mathrm{mg} /$ $\mathrm{kg}$ ) with or without amlodipine $(0.1$ or $0.4 \mathrm{mg} / \mathrm{kg}$ ) are shown in Fig. 4. The relevant pharmacokinetic parameters of warfarin are listed in Table 2. Amlodipine had no effect on the pharmacokinetic parameters of warfarin given intravenously although it exhibited a significant effect on the bioavailability of warfarin given orally, suggesting that CYP3A4-mediated metabolism was inhibited by amlodipine in the rats.

\section{DISCUSSION}

Warfarin is an anticoagulant that has been used to prevent

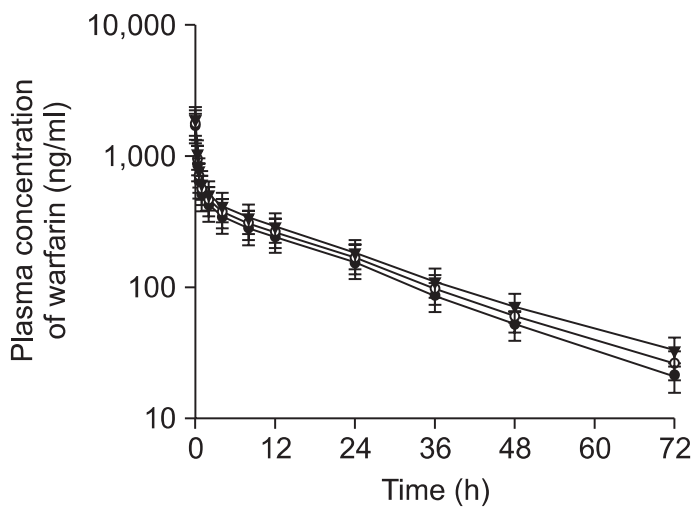

Fig. 4. Mean arterial plasma concentration-time profiles of warfarin after intravenous administration of warfarin $(0.05 \mathrm{mg} / \mathrm{kg})$ without $(\boldsymbol{O})$ or with $0.1 \mathrm{mg} / \mathrm{kg}(\bigcirc)$ and $0.4 \mathrm{mg} / \mathrm{kg}(\boldsymbol{\nabla})$ of amlodipine in rats. Bars represent the standard deviation $(n=6)$.

Table 2. Mean pharmacokinetic parameters of warfarin after intravenous administration of warfarin $(0.05 \mathrm{mg} / \mathrm{kg})$ with or without amlodipine $(0.1$ and $0.4 \mathrm{mg} / \mathrm{kg}$ ) in rats

\begin{tabular}{lccc}
\hline \multirow{2}{*}{ Parameters } & \multirow{2}{*}{\begin{tabular}{c} 
Control without \\
\cline { 3 - 4 }
\end{tabular}} & \multicolumn{2}{c}{ With amlodipine } \\
\cline { 3 - 4 } amlodipine & $0.1 \mathrm{mg} / \mathrm{kg}$ & $0.4 \mathrm{mg} / \mathrm{kg}$ \\
$\mathrm{CL}(\mathrm{ml} / \mathrm{min} / \mathrm{hg})$ & $10149 \pm 2230$ & $11275 \pm 2254$ & $12845 \pm 2565$ \\
$\mathrm{t}_{1 / 2}(\mathrm{~h})$ & $9.8 \pm 2.7$ & $8.9 \pm 2.4$ & $7.6 \pm 2.0$ \\
& $18.1 \pm 3.7$ & $18.9 \pm 3.9$ & $20.2 \pm 4.2$ \\
\hline
\end{tabular}

Mean \pm S.D. $(n=6)$, AUC: area under the plasma concentrationtime curve from time 0 to infinity, CL: total body clearance, $t_{1 / 2}$ : terminal half-life.

thromboembolism including pulmonary embolism, cardiovascular disease and stroke. Scheduled monitoring and dosage adjustment are critical to maintain efficacy and to prevent bleeding events. Warfarin has a narrow therapeutic range and its efficacy can be influenced by drug-drug interactions, drugfood interactions, genetic factors and patient characteristics (Kaminsky and Zhang, 1997; Hirsh et al., 1998).

CYPs enzymes make a considerable contribution to the first-pass metabolism and oral bioavailability of many drugs. Moreover, induction or inhibition of CYPs may be responsible for significant drug and drug interactions (Cummins et al., 2002; Benet et al., 2003). Modulators of P-gp can enhance or limit the permeability of a number of therapeutic agents that are considered substrates of this efflux pump protein (Darvari and Boroujerdi, 2004). Therefore amlodipine, a dual inhibitor against both CYP3A4 and P-gp, should have a great impact on the bioavailability of many drugs where CYP3A4 metabolism as well as P-gp mediated efflux is the major barrier to the systemic bioavailability and thus could act synergistically to limit oral bioavailability of its substrates (Saeki et al., 1993; Wacher et al., 2001).

As shown in Fig. 1, amlodipine exhibited inhibitory effect against CYP3A4-mediated metabolism with the $\mathrm{IC}_{50}$ values of $9.1 \mu \mathrm{M}$. A cell-based P-gp activity test using rhodamine-123 also showed that amlodipine did not significantly inhibit P-gp activity (Fig. 2). As amlodipine is an inhibitor of CYP3A4, con- 
comitant use of the drug might play a role in the wide inter-individual variability in the response to drugs (Choi et al., 2006; Choi et al., 2008). Most calcium channel blockers (verapamil, nifedipine, diltiazem, barnidipine) also have inhibitory effect on the drug transporter P-gp, which mediates drug's intestinal absorption (Yusa and Tsuruo, 1989; Wacher et al., 2001). However, Harmsze et al. (2010) reported that amlodipine have poor inhibitory effects on the drug transporter P-gp.

Compared to those animals in the oral control group (warfarin without amlodipine), the AUC of warfarin was significantly greater by $26.5-53.5 \%$, and the $C_{\max }$ was significantly higher by $26.2 \%$ after oral administration of warfarin with amlodipine (Table 1). Consequently, the absolute bioavailability of warfarin with amlodipine was significantly greater by $61.7-72.5 \%$ compared to that in the control group (47.4\%). In contrast, amlodipine had no effect on any pharmacokinetic parameters of warfarin given intravenously, implying that coadministration of amlodipine could inhibit CYP3A4-mediated metabolism of warfarin, resulting in reducing intestinal or hepatic first-pass metabolism (Abernethy et al., 1991; Stoysich et al., 1996; Wallin et al., 2002). These results were consistent with the results reported by Nishio et al. (2005).

In conclusion, the enhanced oral bioavailability of warfarin by amlodipine suggests that CYP3A4-mediated metabolism were inhibited rather than P-gp-mediated efflux or renal elimination of warfarin. In further clinical studies, the dosage regimen of warfarin might be readjusted when used concomitantly with amlodipine in the patients.

\section{REFERENCES}

Abernethy, D. R., Kaminsky, L. S. and Dickinson, T. H. (1991) Selective inhibition of warfarin metabolism by diltiazem in humans. J. Pharmacol. Exp. Ther. 257, 411-415.

Abernethy, D. R. (1992) Pharmacokinetics and pharmacodynamics of amlodipine. Cardiology 80, 31-36.

Benet, L. Z., Cummins, C. L. and Wu, C. Y. (2003) Transporter-enzyme interactions: implications for predicting drug-drug interactions from in vitro data. Curr. Drug Metab. 4, 393-398.

Choi, J. S., Piao, Y. J. and Han, H. K. (2006) Phatmacokinetics interaction between Fluvastatin and Diltiazem in rats. Biopharm. Drug Dispos. 27, 437-441.

Choi, D. H., Chang, K. S., Hong, S. P. and Choi, J. S. (2008) Effect of atrovastatin on intravenous and oral pharmacokinetics of verapamil in rats. Biopharm. Drug Dispos. 29, 45-50.

Crespi, C. L., Miller, V. P. and Penman, B. W. (1997) Microtiter plate assays for inhibition of human, drug-metabolizing cytochromes P450. Anal. Biochem. 248, 188-190.

Cummins, C. L., Jacobsen, W. and Benet, L. Z. (2002) Unmasking the dynamic interplay between intestinal P-glycoprotein and CYP3A4. J. Pharmacol. Exp. Ther. 300, 1036-1045.

Darvari, R. and Boroujerdi, M. (2004) Concentration dependency of modulatory effect of amlodipine on P-glycoprotein efflux activity of doxorubicin - a comparison with tamoxifen. J. Pharm. Pharmacol. 56, 985-991.

Han, C. Y., Cho, K. B., Choi, H. S., Han, H. K. and Kang, K. W. (2008) Role of FoxO1 activation in MDR1 expression in adriamycin-resistant breast cancer cells. Carcinogenesis 29, 1837-1844

Harmsze, A. M., Robijns, K., van Werkum ,J. W., Breet, N. J., Hackeng, C. M., Ten Berg, J. M., Ruven, H. J., Klungel, O. H., de Boer, A. and Deneer, V. H. (2010) The use of amlodipine, but not of Pglycoprotein inhibiting calcium channel blockers is associated with clopidogrel poor-response. Thromb. Haemost. 103, 920-925.

Hirsh, J., Dalen, J. E., Anderson, DR., Poller, L., Bussey, H., Ansell, J., Deykin, D. and Brandt, J. T. (1998) Oral anticoagulants: mechanism of action, clinical effectiveness, and optimal therapeutic range. Chest 114, 445-469.

Holford, N. H. G. (1986) Clinical pharmacokinetics and pharmacodynamics of warfarin: understanding the dose-effect relationship. Clin. Pharmacokinet. 11, 483-504.

Kaminsky, L. S. and Zhang, Z. Y. (1997) Human P450 metabolism of warfarin. Pharmacol. Ther. 73, 67-74.

Kim, K. A., Park, P. W. and Park, J. Y. (2009) Effect of cytochrome P450 3A5*3 genotype on the stereoselective pharmacokinetics of amlodipine in healthy subjects. Chirality 21, 485-491.

Kungys, G., Naujoks, H. and Wanner, C. (2003) Pharmacokinetics of amlodipine in hypertensive patients undergoing haemodialysis. Eur. J. Clin. Pharmacol. 59, 291-295.

Meredith, P. A. and Elliott, H. L. (1992) Clinical pharmacokinetics of amlodipine. Clin. Pharmacokinet. 22, 22-31.

Mungall, D. R. (1985) Population pharmacokinetics of racemic warfarin in adult patients. J. Pharmacokinet. Biopharm. 13, 213-227.

Nishio, S., Watanabe, H., Kosuge, K., Uchida, S., Hayashi, H. and Ohashi, K. (2005) Interaction between amlodipine and simvastatin in patients with hypercholesterolemia and hypertension. Hypertens. Res. 28, 223-227.

Saeki, T., Ueda, K., Tanigawara, Y., Hori, R. and Komano, T. (1993) P-glycoprotein-mediated transcellular transport of MDR-reversing agents. FEBS Lett. 324, 99-102.

Scordo, M. G., Pengo, V., Spina, E., Dahl, M. L., Gusella, M. and Padrini, R. (2002) Influence of CYP2C9 and CYP2C19 genetic polymorphisms on warfarin maintenance dose and metabolic clearance. Clin. Pharmacol. Ther. 72, 702-710.

Stoysich, A. M., Lucas, B. D., Mohiuddin, S. M. and Hilleman, D. E. (1996) Further elucidation of pharmacokinetic interaction between diltiazem and warfarin. Int. J. Clin. Pharmacol. Ther. 34, 56-60.

Wacher, V. J., Salphati, L. and Benet, L. Z. (2001) Active secretion and enterocytic drug metabolism barriers to drug absorption. Adv. Drug Deliv. Rev. 46, 89-102.

Wallin, R., Sane, D. C. and Hutson, S. M. (2002) Vitamin K 2,3-epoxide reductase and the vitamin K-dependent gamma-carboxylation system. Thromb. Res. 108, 221-226.

Yusa, K. and Tsuruo, T. (1989) Reversal mechanism of multidrug resistance by verapamil: direct binding of verapamil to P-glycoprotein on specific sites and transport of verapamil outward across the plasma membrane of K562/ADM cells. Cancer Res. 49, 5002-5006.

Zhu, M., Chan, K. W., Ng, L. S., Chang, Q., Chang, S. and Li. R. C. (1999) Possible influences of ginseng on the pharmacokinetics and pharmacodynamics of warfarin in rats. J. Pharm. Pharmacol. 51, 175-180. 